\title{
Double-blind clinical trial of 5-hydroxytryptophan in a case of Lesch-Nyhan syndrome
}

\author{
C. D. FRITH, EVE C. JOHNSTONE, M. H. JOSEPH, R. J. POWELL, \\ AND R. W. E. WATTS \\ From the Divisions of Psychiatry and Inherited Metabolic Diseases, \\ MRC Clinical Research Centre, Watford Road, Harrow, Middlesex
}

SYNOPSIS 5-Hydroxytryptophan (5-HTP) treatment of a single case of Lesch-Nyhan syndrome showing compulsive self-mutilation, athetoid movements, and characteristic clinical biochemical picture was studied on a double-blind basis. 5-HTP or placebo was administered for seven fortnightly treatment blocks. 5-HTP produced a significant reduction of athetoid movement and a sedative effect but did not improve the patient's mood or reduce self-mutilation.

The Lesch-Nyhan syndrome (Lesch and Nyhan, 1964), as originally described, comprised mental retardation, choreoathetosis, spasticity, compulsive self-mutilation, aggressiveness, hyperuricaemia, hyperuricaciduria, urinary calculi, and juvenile gout. Some patients also have megaloblastic anaemia. The syndrome is associated with a gross deficiency, and often undetectable levels, of hypoxanthine phosphoribosyltransferase (HGPRT, EC 2.4.2.8) activity in the patient's erythrocytes and other tissues, although the catalytically incompetent enzyme can be demonstrated immunologically (Arnold et al., 1972; Müller and Steinberger, 1974). However, the degree of any residual enzyme activity demonstrable in erythrocytes does not closely relate to the severity of the clinical manifestations.

The compulsive self-mutilation is a most striking and particularly distressing feature of the syndrome. Mizuno and Yugari (1974) reported an open trial of 5-hydroxytryptophan (5-HTP) in which self-mutilation was completely relieved in four cases of Lesch-Nyhan syndrome. A decision to treat with 5-hydroxytryptophan would probably involve committing the child to a lifelong course of medication with a new psychotropic drug, and we therefore

(Accepted 5 March 1976.) considered that every effort should be made to establish firmly the efficacy of the drug in such a way that subjective factors were as far as possible excluded from the judgements of the observers. This would seem to be particularlyo important since it is well known that the severit of the manifestations of this disorder fluctuate in intensity and that apparent improvement sometimes occurs if the child's environment is changed, especially when he is admitted to a paediatric ward for a period of investigation or for treatment of an intercurrent condition.

This paper reports the design and results of a double-blind trial of 5-hydroxytryptophan treatment in conjunction with a peripheral decarboxylase inhibitor in a case of the LeschNyhan syndrome using an objective rating procedure.

\section{METHODS}

Analytical Uric acid, creatinine, and protein were determined as previously reported (Watts et al., 1974); erythrocyte hypoxanthine phosphoribosyltransferase and adenine phosphoribosyltransferase (APRT, EC 2.4.2.7) as described by Craft et al. (1970) but using $\mathrm{pH} 8.0$ rather than $\mathrm{pH} 7.5$ tris-Cl buffer $(0.1 \mathrm{M})$; erythrocyte ribosephosphate pyrophosphokinase (PRPP synthetase, EC 2.7.6.1) as described by Fox and Kelley (1971); erythrocyte phosphoribosylpyrophosphate (PRPP) as described 
by Gordon et al. (1974). The immunoassay of the catalytically incompetent HGPRT protein crossreacting material or CRIM (Arnold et al., 1972) was kindly performed by Professor W. N. Kelly, Department of Medicine, Duke University, Durham, North Carolina, USA. Plasma 5-HTP levels were determined by the method of Joseph and Baker (in preparation). 5-HTP was extracted into acid butanol, back extracted into dilute acid, and separated from 5-HT using a liquid cation exchange reagent. Quantitation was via fluorimetric assay after condensation with o-phthalaldehyde (Maickel and Miller, 1966) with the addition of cysteine.

\section{PATIENT}

The patient (D.H.) is the $6 \frac{1}{2}$ year old boy previously described by Watts et al. (1974) when he was $4 \frac{1}{2}$ years old. He remains choreoathetoid and markedly hypotonic. Compulsive self-mutilation continues and the patient now shows evidence of insight into this aspect of his condition. Megaloblastic anaemia, renal complications, and gout have not developed. Psychometric examination (Miss S. Gilbert) using a slightly modified Peabody Picture Vocabulary Test gave a raw score of 44 and a mental age of 4 years 3 months when his chronological age was 6 years 5 months. This result may be an underestimate because of the patient's difficulty with expressive language and his inevitably limited experience. It seems likely that this child's prognosis will be governed more by his physical than by his mental handicap. The present studies were undertaken when he was taking allopurinol (100 mg daily). The biochemical findings, which are characteristic of the Lesch-Nyhan syndrome, are presented in Table 1.

DESIGN OF TRIAL The trial was divided into a series of fortnightly blocks during each of which the patient received either drug or placebo. These treatments were assigned on a random basis which was unknown to the patient, his parents, the ward staff, or those responsible for assessing changes in behaviour. For the first half of each fortnight the patient was at home and for the second half in hospital. The major assessments of behaviour change were made in hospital during the second week of each treatment block at which time it was considered that drug effects would have stabilized and transient changes in behaviour would have ceased.

DRUG ADMINISTRATION Drugs were administered in gelatine capsules; placebos for each drug contained lactose. 5-HTP (Cambrian Chemicals,
TABLE 1

DIAGNOSTIC BIOCHEMISTRY

\begin{tabular}{|c|c|c|}
\hline & atient & $\begin{array}{l}\text { Normal range in } \\
\text { our laboratory }\end{array}$ \\
\hline $\begin{array}{l}\text { HGPRT } \\
\left(\mathrm{nmol} \cdot \mathrm{mg} \cdot \text { protein }^{-1} \cdot \text { hour }^{-1}\right)\end{array}$ & 0 & $103(\mathrm{SD}=18 ; \mathrm{n}=13)$ \\
\hline APRT $\left(\right.$ nmol $\cdot \mathrm{mg} \cdot$ protein $^{-1} \cdot$ hour $\left.^{-1}\right)$ & 54 & $19(\mathrm{SD}=3.0 ; \mathrm{n}=31)$ \\
\hline $\begin{array}{l}\text { PRPP synthetase } \\
\left(\mathrm{nmol} \cdot \mathrm{mg}^{\text {protein }}{ }^{-1} \cdot \text { hour }^{-1}\right)\end{array}$ & 23 & $25(\mathrm{SD}=6.3 ; \mathrm{n}=10)$ \\
\hline PRPP (pmol·mg·protein ${ }^{-1}$ ) & 97 & $16(\mathrm{SD}=2.6 ; n=31)$ \\
\hline $\begin{array}{l}\text { Serum uric acid }\left(\mathrm{mg} \cdot \mathrm{dl}^{-1}\right) \\
(\mu \mathbf{M})\end{array}$ & $\begin{array}{l}9.0 \\
536\end{array}$ & $\begin{array}{l}1.2-6.8^{*} \\
72-405\end{array}$ \\
\hline Urine uric acid/creatinine & 3.2 & $1.8+$ \\
\hline CRIM ${ }_{+}^{+}$ & + & $\therefore$ \\
\hline
\end{tabular}

* Data reported by Harkness and Nicol (1969) for boys age 0-13 years, these workers used the method of Liddle et al. (1959). The values obtained for younger children are in the lower part of this range with a fairly abrupt rise as puberty approaches.

$\dagger$ The limit of the upper range for boys of this patient's age (Kaufman et al., 1968).

$\ddagger$ CRIM $+=$ patient's red cells contain protein which cross-reacts with antiserum prepared against purified hypoxanthine phosphoribosyltransferase (HGPRT EC 2.4.2.8) (Arnold et al., 1972).

Croydon) was administered at a dose of $100 \mathrm{mg} /$ day in four equal doses, Carbidopa (Merck, Sharp and Dohme; Hoddesdon) at a dose of $50 \mathrm{mg} /$ day in two equal doses. This amount of 5-HTP is equivalent to the maximum dose $(8 \mathrm{mg} / \mathrm{kg})$ used in the study by Mizuno and Yugari (1974) and pilot studies had shown that this was well tolerated by our patient. A peripheral decarboxylase inhibitor was not used in their study; it should potentiate the central effects of 5-HTP and therefore enhance any effects on behaviour. Placebo tablets for both drugs were administered during non-treatment weeks.

After 14 weeks (seven treatment blocks, four on drug and three on placebo) it was clear that there was no obvious difference in behaviour between treatment and no treatment periods, particularly with regard to self-mutilation. In addition the weekly shuttle between home and hospital was becoming distressing both for the patient and his parents. It was therefore decided to terminate the trial.

ASSESSMENT OF BEHAVIOUR CHANGE Six behavioural rating scales were designed specifically for the patient on the basis of observations made before the start of the trial. Two scales related to abnormal behaviour, self-mutilation, and choreoathetoid movement, and the others concerned normal behaviour, 
TABLE 2

SCALE OF SPEECH QUALITY

\begin{tabular}{l} 
(Evoked speech occurs in response to question) \\
\hline $\begin{array}{l}\text { Speech impairment scale } \\
\text { 0. Both spontaneous and evoked speech comprehensible and } \\
\text { minimally disturbed }\end{array}$ \\
1. Spontaneous speech difficult to understand \\
2. Only evoked speech understandable to any extent \\
3. Only a few expected words understandable ('yes', 'no', names of \\
requested toys, etc.) \\
4. All speech incomprehensible or no speech in spite of attempts to \\
elicit it
\end{tabular}

mood, attention, voluntary movement, and speech quality. The scales were modelled on the Goldberg Psychiatric rating scales (Goldberg et al., 1970) and consisted of five points each defined by concrete examples of behaviour. The scales ranged from the worst example of the particular behaviour (score 4) observed during the pre-trial observation period to the best improvement in behaviour that might be expected if the treatment were successful (score 0 ). Table 2 lists the five levels of behaviour for the scale of speech quality. During his weeks in hospital the patient was rated independently by six observers each day. The ratings were based on a 15-minute observation period during which time the patient was generally playing with ward staff or the observers. To obtain a measure of the reliability of the rating scales, uncontaminated by genuine fluctuations of the patient's behaviour, four of the observers worked in pairs observing the same behaviour, but arriving at independent ratings of it.

In addition to the rating scales, an objective index of movement was provided by an activity meter consisting of a modified self-winding wrist-watch which was attached to the patient's left ankle for 10 minutes each day. Since the patient is confined to a wheel-chair with his legs hanging freely, readings from this meter were an index of amount of athetoid movement. It was also noted each day which of the various measures adopted to prevent self-mutilation was being used. These varied from splints and bandages on both arms and hands to no restraint on either arm and hand. These measures were a further indication of the tendency to self-mutilation.

\section{RESULTS}

DRUG LEVELS As expected, 5-hydroxytryptophan was not detectable in plasma before treatment, or in any of the placebo periods (Table 3). It was detectable, however, as long as
TABLE 3

PLASMA LEVELS OF 5-HYDROXYTRYPTOPHAN

\begin{tabular}{|c|c|c|c|c|}
\hline Date & $\begin{array}{c}\text { Treatment } \\
\text { period }\end{array}$ & $\begin{array}{c}\text { Carbidopa } \\
(m g / d a y)\end{array}$ & $\begin{array}{c}5-H T P \\
(m g / d a y)\end{array}$ & $\begin{array}{c}\text { Plasma } \\
5-H T P \\
(\mu g / m l \\
10 h \\
\text { post-drug) }\end{array}$ \\
\hline 6 Jan. 75 & & 0 & 0 & ND \\
\hline 13 Feb. 75 & & 0 & 30 & 0.07 \\
\hline 14 Mar. 75 & & 50 & 100 & 0.68 \\
\hline 19 May 75 & 1 & 0 & 0 & ND \\
\hline 5 June 75 & 2 & 50 & 100 & 0.31 \\
\hline 17 June 75 & 3 & 50 & 100 & 0.42 \\
\hline 1 July 75 & 4 & 0 & 0 & ND \\
\hline 15 July 75 & 5 & 50 & 100 & $\begin{array}{l}(1.79 \\
\text { h post-drug })\end{array}$ \\
\hline 29 July 75 & 6 & 0 & 0 & ND \\
\hline 12 Aug. 75 & 7 & 50 & 100 & 0.36 \\
\hline
\end{tabular}

$\mathrm{ND}=$ not detectable.

10 hours after administration of 5-HTP. A higher level was observed $0.5 \mathrm{hr}$ after administration; the results reported are consistent witho potentiation of the 5-HTP by inhibition of peripheral decarboxylation, but ethical con $\vec{\Omega}$ 음 siderations precluded more detailed pharmacokinetic analysis.

OVERALL MOOD It was found that a number of the rating scales were related closely to one another. An unhappy mood was associated with lapses of attention, poor voluntary movement, and unclear speech. Therefore these four scales were combined to give one index of overall mood. The reliability of this scale was 0.57 (based on 20 observations) when the ratings being compared were of the same behaviour. However, the correlations between ratings made at different times of the same day fell to 0.21 , suggesting that there were considerable fluctuations in mood during the course of a day. Overall mood was somewhat worse during drug periods than during placebo periods, but not significantly so (Fig. 1), indicating that 5-HTP did not improve this patient's overall mood.

It was apparent from the parent's ratings when the patient was at home that there was a worsening of mood at the beginning of each placebo period (and hence immediately after the patient had stopped taking 5-HTP). There were not enough data for this effect to be significant, but it suggests that some mild withdrawal effect was occurring. 
Mean rating of overall mood state by six observers (inter-rater reliability $=0.571$

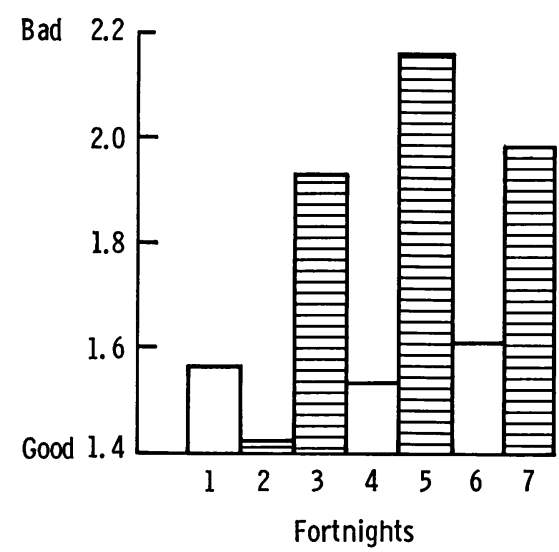

FIG. 1 Effects of 5-HTP on overall mood. Treatment: $匚=5-H T P . \square=$ Placebo. No significant effect of 5-HTP on mood.
ATHETOID MOVEMENT Ratings of athetoid movement were fairly reliable $(r=0.68)$ and the daily fluctuations were relatively small $(r=0.54)$. Furthermore, there was close agreement between the ratings and the readings of the wrist watch activity meter $(r=0.61)$. The activity meter indicated that there was significantly less athetoid movement during periods on drug (Mann-Whitney $U$ test, $\mathrm{P}<0.05$ ). Thus 5-HTP reduced athetoid movement in this patient (Fig. 2).

Certain spontaneous observations made by the raters were related to this finding. At least three observers commented that the patient

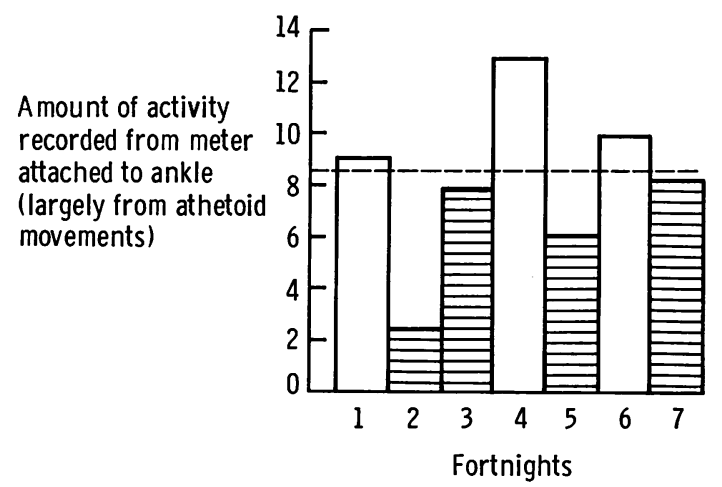

FIG. 2 Effects of 5-HTP on athetoid movement. Treatment: $\square=5-H T P . \square=$ Placebo. 5-HTP reduces athetoid movement $(P<0,05)$. appeared sleepy, quiescent, or flaccid during each drug period; no such comments were made during placebo periods (Fig. 3). Thus 5-HTP was having a significant sedative effect on this patient (Mann-Whitney $U$ test, $P<0.05$ ).

Number of observers rating patient as sleepy/floppy

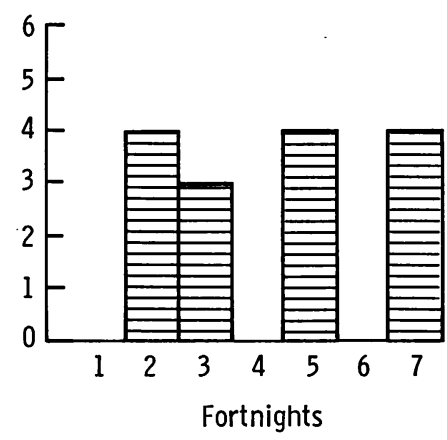

FIG 3. Effects of 5-HTP on arousal/muscle tone. Treatment : $\equiv=5-H T P . \square=$ Placebo. 5-HTP increases sleepiness $(P<0.05)$.

SELF MUTILATION In terms of the measures necessary to restrain the patient there were no differences between drug and placebo periods either when the patient was in hospital or at home.

It was clearly not desirable to remove the splints and observe the self-mutilation several times a day and so the majority of the ratings were made while the patient was restrained. As a 


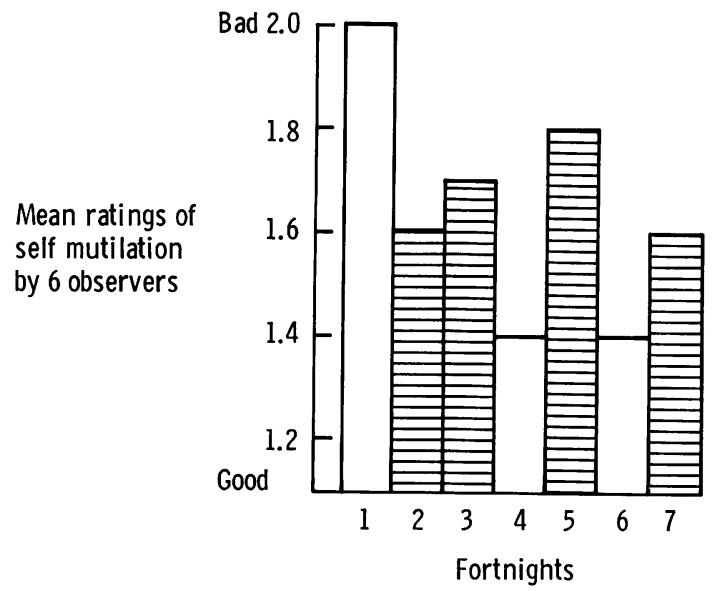

FIG. 4 Effects of 5-HTP on self-mutilation. Treatment: $\square=5$-HTP. $\square=$ Placebo. 5-HTP does not reduce self-mutilation.

result, the ratings of this behaviour were somewhat unreliable $(r=0.40)$. On the basis of the average ratings of all six observers self-mutilation tended to be worse during drug periods (Fig. 4), but not significantly so. The same result was obtained when only those ratings made with the patient unrestrained were considered.

\section{DISCUSSION}

Mizuno and Yugari (1974) used 5-HTP to treat self-mutilation on the basis that this was an autoaggresive phenomenon, and that 5-HTP prevented the development of isolation-induced aggressive behaviour in rats and mice. Although we feel that self-stimulation in Lesch-Nyhan syndrome should not be regarded simply as autoaggressive behaviour, since physical restraint appears to prevent it without frustration or displacement to other autoaggressive behaviours, we did feel that there was additional experimental work supporting a possible beneficial action of 5-HTP. The presence of HGPRT in well-washed synaptosomes (Gutensohn and Guroff, 1972) points to a possible role of purine salvage in synaptic transmission. The lack of HGPRT in the Lesch-Nyhan syndrome will lead to a deficiency of GMP, and hence of GTP in vulnerable tissues such as the brain and bone marrow. This would in turn lead to a deficiency of cyclic GMP. This nucleotide is thought to be a modulator of certain metabolic processes including cell division (Hadden et al., 1972; Shields, 1974), cholinergic receptor action (Weight et al., 1974; Kebabian et al., 1975), and, at least extracerebrally (Sandler et al., 1975), of serotonergic receptor action. Thus, a disturbance in the balance between cyclic nucleotides or between serotonergic and catecholaminergic systems in Lesch-Nyhan syndrome might be restored by increased 5-HT synthesis and receptor stimulation. The reports of increased dopamine- $\beta$-hydroxylase (dopamine- $\beta$-monooxygenase, EC 1.13.17.1) activity in the LeschNyhan syndrome (Rockson et al., 1974), of the production of compulsive gnawing, and stereotyped behaviours in rats and cats by amphetamine (Randrup and Munkvad, 1966; Wallach and Gershon, 1971), and of the production of autoaggression in experimental animals by feeding caffeine and theophylline (Nyhan, 1968; Morgan et al., 1970), which block the degradation of CAMP and cGMP by inhibition of $3^{\prime}: 5^{\prime}-$ cyclic AMP phosphodiesterase (EC 3.1.4.17) would be broadly consistent with this formulation.

However, in the present study, although it was clear that 5-HTP affected the behaviour of this patient, it did not reduce self-mutilation behaviour, nor did it improve the patient's overall mood. It seems unlikely that this failure to affect self-mutilation was due to an insufficient dose of 5-HTP. The dose the patient received was equal to the maximum dose used by Mizuno and Yugari (1974). The plasma levels of 5-HTP that were measured confirmed that the patient in fact received the active drugs and placebo in accordance with the design of the trial, that the 5-HTP was absorbed, and that raised plasma levels persisted until the next dose was administered. It is possible that the addition of Carbidopa, by inhibiting peripheral effects, also prevented an effect on self-mutilation behaviour. However, a previous uncontrolled study suggested that 5-HTP alone administered for six weeks had equally little effect on this patient's self-mutilation.

5-HTP did reduce our patient's involuntary movements and produce a general appearance 
of sleepiness. It is possible that a sufficiently large dose of 5-HTP would reduce self-mutilation as a secondary consequence of this sedating effect. Such an effect might account for the results of Mizuno and Yugari (1974).

Self-mutilation varied markedly in our patient. It increased when he was frightened or frustrated and reduced when he was concentrating on some interesting occupation. The patient is very much aware of the undesirability of the selfmutilation. He becomes very agitated if the restraining splints or bandages are removed from his hands and can only be calmed by their replacement. He will try and impose his own restraints by such measures as sitting on his hands. Some of this behaviour is in line with Duker's (1975) suggestion that self-mutilation behaviour is learned by Lesch-Nyhan patients as a method of gaining attention. Duker has demonstrated that the behaviour is under the control of environmental influences and has achieved some success in reducing self-mutilation using behaviour modification techniques. If self-mutilation is indeed influenced by the patient's environment, then the marked change in environment brought about when the patient is moved to hospital for an intensive investigation of a new treatment might well induce a similarly marked change in self-mutilation behaviour. This possibility was not controlled for in the study by Mizuno and Yugari (1974) and indeed can only be controlled for by using a double-blind study as described here.

Lastly, it is of course possible that our single case of Lesch-Nyhan syndrome is unusual in his failure to respond to 5-HTP. It is a disadvantage of single case studies that it is hard to generalize beyond the patient in question. It would therefore be desirable to repeat this kind of study with other cases of Lesch-Nyhan syndrome. Reports of other informal trials of 5-HTP lead us to suspect that our patient is not uncharacteristic in failing to reduce self-mutilation behaviour as a specific response to 5-HTP. It would still be possible that this patient, or indeed others, might respond to other measures designed to stimulate serotonergic neurones, the effects of which might be more specific.

We wish to thank Edna Brown, Lynne Dalton, and Marilyn James for assisting with ratings, H. F. Baker for skilful technical assistance with plasma 5-HTP estima- tion, and $\operatorname{Dr}$ T. J. Crow for helpful discussions. We also wish to thank the Department of Bioengineering for the wrist-watch activity meter, and Merck Sharp and Dohme and Cambrian Chemicals for providing the Carbidopa and 5-HTP respectively. Particular thanks are due to our patient, his parents, and the nursing staff of Carol Ward.

\section{REFERENCES}

Arnold, W. J., Meade, T. J., and Kelley, W. N. (1972). Hypoxanthine-guanine phosphoribosyl transferase: characteristics of the mutant enzyme in erythrocytes from patients with the Lesch-Nyhan syndrome. Journal of Clinical Investigation, 51, 1805-1812.

Craft, J. A., Dean, B. M., Watts, R. W. E., and Westwick, W. J. (1970). Studies on human erythrocyte IMP: pyrophosphate phosphoribosyl-transferase. European Journal of Biochemistry, 15, 367-373.

Duker, P. (1975). Behaviour control of self-biting in a Lesch-Nyhan patient. Journal of Mental Deficiency Research, 19, 11-19.

Fox, I. H., and Kelley, W. N. (1971). Human phosphoribosyl pyrophosphate synthetase: distribution, purification and properties. Journal of Biological Chemistry, 246, 5739-5748.

Goldberg, D. P., Cooper, B., Eastwood, M. R., Kedward, H. B., and Shepherd, M. (1970). A standardised psychiatric interview for use in community surveys. British Journal of Preventive and Social Medicine, 24, 18-23.

Gordon, R. B., Thompson, L., and Emerson, B. T. (1974). Erythrocyte phosphoribosylpyrophosphate concentrations in heterozygotes for hypoxanthine-guanine phosphoribosyltransferase deficiency. Metabolism, 23, 921-927.

Gutensohn, W., and Guroff, G. (1972). Hypoxanthineguanine-phosphoribosyl transferase from rat brain (purification, kinetic properties, development and distribution). Journal of Neurochemistry, 19, 2139-2150.

Hadden, J. W., Hadden, E. M., Haddox, M. K., and Goldberg, N. D. (1972). Guanosine $3^{\prime}: 5^{\prime}$-cyclic monophosphate: a possible intracellular mediator of mitogenic influences in lymphocytes. Proceedings of the National Academy of Sciences, USA, 69, 3024-3027.

Harkness, R. A., and Nicol, A. D. (1969). Plasma uric acid levels in children. Archives of Disease in Childhood, 44, 773-778.

Kaufman, J. M., Greene, M. L., and Seegmiller, J. E. (1968). Urine uric acid to creatinine ratio-a screening test for inherited disorders of purine metabolism. Journal of Paediatrics, 73, 583-588.

Kebabian, J. W., Bloom, F. E., Steiner, A., and Greengard, P. (1975). Neurotransmitters increase cyclic nucleotides in postganglionic neurons: immunocytochemical demonstration. Science, 190, 151-159.

Lesch, M., and Nyhan, W. L. (1964). A familial disorder of uric acid metabolism and central nervous system function. American Journal of Medicine, 36, 561-570. 
Liddle, L., Seegmiller, J. E., and Laster, L. (1959). Enzymatic spectrophotometric method for determination of uric acid. Journal of Laboratory and Clinical Medicine, 54, צ03-S08.

Maickel, R. P., and Miller, F. P. (1966). Fluorescent products formed by reaction of indole derivatives and o-phthalaldehyde. Analytical Chemistry, 38, 1937-1938.

Mizuno, T., and Yugari, Y. (1974). Self mutilation in the Lesch-Nyhan syndrome. Lancet, $1,761$.

Morgan, L. L., Schneidermann, N., and Nyhan, W. L. (1970). Theophylline; induction of self biting in rabbits. Psychonomic Science, 19, 37-38.

Müller, M. M., and Steinberger, H. (1974). Biochemische und immunologische Untersuchungen der Hypoxanthin-Guanin-Phosphoribosyltransferase in den Erythrozyten von Lesch-Nyhan Patienten. Wiener klinische Wochenschrift, 86, 127-131.

Nyhan, W. L. (1968). Seminars in the Lesch-Nyhan syndrome: pathology and pathologic physiology, discussion. Federation Proceedings, 27, 1044-1046.

Randrup, A., and Munkvad, I. (1966). Role of catecholamines in the amphetamine excitatory response. Nature, 211, 540.
Rockson, S., Stone, R., van der Weyden, M., and Kelly, W. N. (1974). Lesch-Nyhan syndrome: evidence for abnormal adrenergic function. Science, 186, 934-935.

Sandler, J. A., Clyman, R. I., Manganiello, V. C., and Vaughan, M. (1975). The effect of serotonin (5hydroxytryptamine) and derivatives on guanosine $3^{\prime}, 5^{\prime}$-monophosphate in human monocytes. Journal of Clinical Investigation, 55, 431-435.

Shields, R. (1974). Control of cell growth by the cyclic nucleotide seesaw. Nature, 252, 11-12.

Wallach, M. B., and Gershon, S. (1971). Induction and antagonism of stereotyped behaviour in cats. Pharmacologist, 13, 230.

Watts, R. W. E., McKeran, R. O., Brown, E., Andrews, T. M., and Griffiths, M. I. (1974). Clinical and biochemical studies on treatment of Lesch-Nyhan syndrome. Archives of Disease in Childhood, 49, 693-702.

Weight, F. F., Petzold, G., and Greengard, P. (1974). Guanosine 3',5'-monophosphate in sympathetic ganglia: increase associated with synaptic transmission. Science, 186, 942-944. 